\title{
Can the outcome of spinal cord stimulation in chronic complex regional pain syndrome type I patients be predicted by catastrophizing thoughts?
}

Citation for published version (APA):

Lame, I. E., Peters, M. L., Patijn, J., Kessels, A. G. H., Geurts, J., \& van Kleef, M. (2009). Can the outcome of spinal cord stimulation in chronic complex regional pain syndrome type I patients be predicted by catastrophizing thoughts? Anesthesia and Analgesia, 109(2), 592-599. https://doi.org/10.1213/ane.0b013e3181a9082b

Document status and date:

Published: 01/01/2009

DOI:

10.1213/ane.0b013e3181a9082b

Document Version:

Publisher's PDF, also known as Version of record

\section{Document license:}

Taverne

Please check the document version of this publication:

- A submitted manuscript is the version of the article upon submission and before peer-review. There can be important differences between the submitted version and the official published version of record.

People interested in the research are advised to contact the author for the final version of the publication, or visit the DOI to the publisher's website.

- The final author version and the galley proof are versions of the publication after peer review.

- The final published version features the final layout of the paper including the volume, issue and page numbers.

Link to publication

\footnotetext{
General rights rights.

- You may freely distribute the URL identifying the publication in the public portal. please follow below link for the End User Agreement:

www.umlib.nl/taverne-license

Take down policy

If you believe that this document breaches copyright please contact us at:

repository@maastrichtuniversity.nl

providing details and we will investigate your claim.
}

Copyright and moral rights for the publications made accessible in the public portal are retained by the authors and/or other copyright owners and it is a condition of accessing publications that users recognise and abide by the legal requirements associated with these

- Users may download and print one copy of any publication from the public portal for the purpose of private study or research.

- You may not further distribute the material or use it for any profit-making activity or commercial gain

If the publication is distributed under the terms of Article $25 \mathrm{fa}$ of the Dutch Copyright Act, indicated by the "Taverne" license above, 


\section{Can the Outcome of Spinal Cord Stimulation in Chronic Complex Regional Pain Syndrome Type I Patients Be Predicted by Catastrophizing Thoughts?}

\author{
Inge E. Lamé, $\mathrm{PhD}^{*}$ \\ Madelon L. Peters, PhD+ \\ Jacob Patijn, MD, PhD*
}

Alfons G. Kessels, MD, MScł

José Geurts, MSc*

Maarten van Kleef, MD, PhD*
BACKGROUND: In this study, we examined whether pain catastrophizing is a predictor of spinal cord stimulation (SCS) outcome in patients with complex regional pain syndrome type I (CRPS-I).

METHODS: Participants in this prospective cohort study were 32 patients with chronic CRPS-I, who received permanent SCS after a positive response to test stimulation. Baseline assessment was performed before test stimulation and included questions on demographic variables, disease information, pain intensity, pain catastrophizing, and health-related quality of life (QOL). Follow-up assessment was performed 9 mo after final implantation and included pain intensity, global perceived effect (GPE), and QOL. Successful SCS outcome was defined as a reduction of pain intensity of at least $50 \%$ on a visual analog scale or "much improved" or "total pain relief" on GPE.

RESULTS: After 9 months, 38\% of the patients had a successful outcome in reduced pain intensity and 53\% of the patients in GPE. In addition, improvements were apparent on several of the domains of QOL. However, no evidence was found for the predictive value of pain catastrophizing on the efficacy of SCS in reduction of pain intensity, GPE, or QOL.

CONCLUSIONS: This study showed that the efficacy of SCS in reduction of pain intensity, GPE, and QOL in a well-defined chronic CRPS-I population was not predicted by pain catastrophizing. Therefore, we conclude that a high level of pain catastrophizing in patients with CRPS-I is not a contraindication for SCS treatment. (Anesth Analg 2009;109:592-9) omplex regional pain syndrome (CRPS) is a pain syndrome characterized by extreme pain and dysfunction of the sympathetic nervous system. It is usually restricted to one region of the body, typically an extremity. CRPS is mostly initiated after a traumatic injury or surgical intervention in a limb. Two different types are distinguished: CRPS-I (formerly called reflex sympathetic dystrophy) and CRPS-II (formerly called causalgia). The yearly incidence of CRPS in The Netherlands is 26.2 per 100,000 people (95\% confidence interval [CI]: 23.0-29.7), with the highest incidence occurring between 61 and 70 yr old. ${ }^{1}$ A substantial portion ( $20 \%$ ) of patients with acute CRPS goes on to develop a chronic condition. Although the syndrome

From the *Department of Pain Management and Research Centre, University Hospital Maastricht; +Department of Clinical Psychological Science, University Maastricht; and $\ddagger$ Department of Clinical Epidemiology and Medical Technology Assessment, University Hospital Maastricht, Maastricht, The Netherlands.

Accepted for publication February 5, 2009.

Address correspondence and reprint requests to Inge E. Lamé, MSc, Pain Management and Research Centre, University Hospital Maastricht, P.O. Box 5800, 6202 AZ Maastricht, The Netherlands. Address e-mail to ingelame@telfort.nl, sandra.reijnders@mumc.nl.

Copyright (c 2009 International Anesthesia Research Society DOI: 10.1213/ane.0b013e3181a9082b is relatively rare, it can be seen as a significant medical condition. $^{2,3}$

Treatments for CRPS primarily focus on restoration of function of the affected limb. One of the treatment options is spinal cord stimulation (SCS), which has been recommended especially for patient with CRPS showing a poor response to conservative treatment. ${ }^{2,4,5}$ SCS has been found to be effective in CRPS for pain relief and improvement in quality of life (QOL) ${ }^{4,6-8}$ Despite the evidence of its efficacy, there are still unresolved issues. First, the long-term efficacy of SCS is still under debate. ${ }^{9,10}$ Second, and most important for this study, not all patients profit from this procedure to the same degree. ${ }^{11}$ Adequate selection of patients may avoid unnecessary costs and suffering. ${ }^{10}$ Usually, the actual implantation is preceded by trial stimulation and only patients with a positive response to trial stimulation receive permanent SCS. However, this selection procedure does not guarantee long-term success ${ }^{8}$ and may be supplemented by additional criteria. Prognostic studies on preimplantation predictor variables for successful outcome are needed to establish these criteria and guide clinical decision making.

Prognostic variables for the efficacy of SCS that have emerged from previous studies include dual 
versus single-lead stimulators, site of placement, number of previous operations, and duration of pain before implantation. ${ }^{11,12}$ Demographic variables were not consistently associated with outcome. It has also been suggested that psychological factors may play a role in determining long-term efficacy of SCS. ${ }^{13}$ Only few studies have examined whether psychological factors influence treatment outcome and the evidence is inconclusive. ${ }^{11,13,14}$ This study focuses on the role of one specific psychological factor that may be predictive of outcome in SCS, i.e., pain catastrophizing. Bruehl and Chung ${ }^{15}$ suggested that pain catastrophizing may be critically involved in the maintenance of the primary features of CRPS, and that these dysfunctional cognitions should be addressed before implementing medical treatment strategies. Catastrophic cognitions and incorrect beliefs about the meaning of pain are indeed common in patients with CRPS. ${ }^{16}$ Because of the intensity of pain and the somatic symptoms characteristic of CRPS (e.g., allodynia), patients with CRPS may be especially inclined to assume that pain signals damage. ${ }^{15}$ Catastrophic misinterpretations of pain may be a primary contributor to disuse and in the end may have a deleterious effect on CRPS itself and its responsiveness to treatment. ${ }^{15}$

This study examines whether pain catastrophizing is indeed a predictor of SCS outcome in patients with CRPS-I. Pain catastrophizing was measured before implantation, and outcome in terms of pain reduction, global perceived effect (GPE), and QOL were assessed 9 mo after implantation. We hypothesized that high catastrophizing patients would have a less successful long-term outcome.

\section{METHODS}

\section{Patient Selection}

Participants in this prospective cohort study were selected from the population with CRPS of the outpatient clinic for Pain and Pain Management of the University Hospital Maastricht, The Netherlands. The study complied with the provisions of the Declaration of Helsinki with regard to research involving human subjects and was approved by the medical ethics committee of Maastricht University Hospital in Maastricht, The Netherlands. All patients gave written informed consent. Patients were eligible for inclusion if they met the diagnostic criteria for CRPS established by the International Association for the Study of Pain, with impaired function and symptoms beyond the area of trauma. ${ }^{17}$ Additional inclusion criteria were 1) symptoms limited to one hand or one foot, with the entire hand or foot affected, 2) disease duration of at least $6 \mathrm{mo}, 3)$ no long-term benefits of standard therapy (6 mo of physical therapy, sympathetic blockade, transcutaneous electrical nerve stimulation, and pain medication), and 4) a mean pain intensity of at least 5 on a visual analog scale (VAS) from 0 (no pain) to 10 (worst possible pain), measured with a 4-day pain diary.

Patients were excluded from participation if they suffered from Raynaud's disease, current or previous neurological abnormalities other than CRPS, other conditions affecting the diseased or the contralateral extremity, a blood-clotting disorder or if they used an anticoagulant drug or a cardiac pacemaker.

\section{Test Stimulation and Implantation}

All patients first underwent test stimulation for 1 wk. Only patients showing a positive response after test stimulation received permanent SCS. A positive response to test stimulation was defined as a decrease in pain intensity on the VAS with at least $50 \%$ during the last 4 days of the testing period or a score of a least 6 (much improved) on a seven-point Likert scale measuring GPE. ${ }^{18}$ For details on the technique of test stimulation and permanent implantation, we refer to Kemler et al. ${ }^{19}$

\section{Measures}

\section{Demographic Variables}

Patients recorded their sex, age, marital status, and highest level of education.

\section{Disease Variables}

Duration of pain in months and location of the pain (arm versus leg) were recorded.

\section{Pain Intensity}

Pain intensity was scored on a VAS, with end points "no pain" and "worst possible pain."

\section{Global Perceived Effect}

GPE was measured on a seven-point scale (1, worst ever; 2 , much worse; 3 , worse; 4 , no change; 5 , improved; 6 , much improved; 7 , total pain relief).

\section{Quality of Life}

QOL was measured with the 36-item short-form health survey (SF-36). This instrument was developed during the Medical Outcome Studies of the Rand Corporation and measures general health and QOL. ${ }^{20}$ The SF-36 encompasses eight domains of healthrelated QOL: physical functioning, social functioning, role limitations physical, role limitations emotional, mental health, vitality, bodily pain, and general health perception. All raw scale scores are linearly converted to a $0-100$ scale. Higher scores indicate a higher level of QOL. The psychometric properties of the SF-36 are adequate. $^{20-23}$

\section{Pain Catastrophizing}

Pain catastrophizing was measured with the Dutch version of the Pain Catastrophizing Scale (PCS) (Crombez G, Vlaeyen JWS. The pain catastrophizing scale. Unpublished Dutch/Flemisch translation, 1996). ${ }^{24}$ The PCS is a 13-item instrument. Items are scored on a five-point Likert scale, ranging from 0 (not at all) to 4 
(always), developed to identify catastrophic thoughts or feelings that patients experience in relation to their pain. A sample item for the PCS is "When I'm in pain, I worry all the time about whether the pain will end." The PCS has good psychometric properties. ${ }^{25-27}$

\section{Procedure}

Before their first appointment with the physician, eligible patients received a questionnaire package by mail, which they had to return (Appendix). The questionnaire package included the questions on demographic variables, disease information and pain intensity, the PCS and the SF-36. Next, patients received test implantation for $1 \mathrm{wk}$, and when successful, permanent SCS followed immediately thereafter. Follow-up assessment was performed 9 mo after final implantation. Patients received a questionnaire package (containing questions on pain intensity and GPE and the SF-36) by mail.

\section{Statistical Analysis}

Pain intensity was calculated by averaging the VAS measured for 4 days, three times a day. Successful outcome was defined as an improvement on the VAS of at least $50 \%{ }^{28}$ In addition, for GPE successful outcome was defined as a score of 6 or 7 (i.e., "much improved" or "total pain relief").

Changes in pain and the health-related QOL domains from baseline to follow-up were tested using paired-sample $t$-tests. To give an indication of clinical relevance of the improvement after SCS, effect sizes were calculated by converting a $t$ value into an $r$ value. ${ }^{29}$ We followed the widely accepted suggestions about what constitutes a large, medium, or small effect for a significance test of a sample: $r=0.10$ (small effect), $r=0.30$ (medium effect), and $r=0.50$ (large effect). Logistic regression analysis was used to identify predictors of the dichotomous outcome variables successful pain relief and successful GPE. As potential predictors, we examined demographic variables, pain duration, pain location, pain intensity at baseline, and pain catastrophizing. To reduce the number of predictors, we first conducted univariate analyses, using $t$-tests for continuous and $\chi^{2}$ analyses for categorical variables. Variables that differentiated between patients with or without successful outcome in the univariate analyses were subsequently included in the logistic regression analyses. In order not to miss a potentially important predictor, we used a significance level of 0.10 for these preliminary analyses. Pain catastrophizing was considered our crucial predictor variable and was always entered to the regression.

To ascertain whether PCS scores are normally distributed and regression analysis was allowed, the Kolmorgorov-Smirnov test was performed. Linear regression analysis was used to identify predictors of changes in health-related QOL from baseline to 9 mo follow-up. Significant variables from the previous univariate analyses together with pain catastrophizing
Table 1. Baseline Characteristics of the Complex Regional Pain Syndrome Patients

\begin{tabular}{|c|c|}
\hline Characteristic & $N=32$ \\
\hline \multicolumn{2}{|l|}{ Gender, \% } \\
\hline Men & 21.2 \\
\hline Women & 78.8 \\
\hline Age, yr (SD) [range] & $38.9(10.5)[15-58]$ \\
\hline Pain duration, yr (SD) [range] & 4.5 (3.3) $[0.5-16]$ \\
\hline \multicolumn{2}{|l|}{ Location of pain, $\%$} \\
\hline Arm & 46.9 \\
\hline Leg & 53.1 \\
\hline \multicolumn{2}{|l|}{ Marital status, \% } \\
\hline Married & 75.0 \\
\hline Unmarried & 12.5 \\
\hline Divorced & 6.3 \\
\hline \multicolumn{2}{|l|}{ Education, \% } \\
\hline Lower vocational education & 46.9 \\
\hline Secondary education & 53.1 \\
\hline VAS score mean (SD) [range] & $7.6(1.4)[5.0-10.0]$ \\
\hline PCS score mean (SD) [range] & $31.0(10.2)[2.0-47.0]$ \\
\hline \multicolumn{2}{|l|}{ SF-36 domains } \\
\hline Physical function & 28.8 (24.6) [0-90.0] \\
\hline \multicolumn{2}{|l|}{ Mean (SD) [range] } \\
\hline Social function & $41.3(27.9)[0-100]$ \\
\hline Role limitations physical & $7.5(18.7)[0-75.0]$ \\
\hline Role limitation emotional & $59.5(44.8)[0-100]$ \\
\hline Mental health & $57.8(22.9)[0-96.0]$ \\
\hline Vitality & 39.3 (20.9) [5.0-75.0] \\
\hline Bodily pain & 12.5 (12.8) [0-34.7] \\
\hline General health perception & 50.5 (15.8) [25.0-85.0] \\
\hline
\end{tabular}

were entered as independent variables. Moreover, the analyses for each domain were controlled for baseline level of QOL for that domain. All data were analyzed by using the SPSS Statistical Package, version 15.0, for windows (Chicago, IL). We used a significance level of 0.05 for the logistic and linear regression analyses.

\section{RESULTS}

\section{Description of Population}

Between January 2000 and September 2006, all patients with CRPS-I who were eligible for SCS were referred to our pain clinic. After the inclusion and exclusion criteria, 58 patients were considered for SCS. Of these, 26 patients ( $45 \%$ ) did not receive permanent SCS for the following reasons: insufficient pain reduction after test stimulation $(n=14)$, low pain intensity at the day of test stimulation $(n=2)$, no paresthesias after test stimulation $(n=2)$, refusal of permanent implantation $(n=3)$, or psychological problems $(n=$ 2 ). For three patients no follow-up assessment was available. The final study population thus consisted of 32 patients with chronic CRPS-I. Baseline characteristics are summarized in Table 1.

\section{SCS Outcome at Follow-up}

Pain relief on the VAS of at least $50 \%$ was reported by 12 patients (38\%). Successful outcome on the GPE (much improved or total pain relief) was reported by 17 patients (53\%). In addition, 10 patients (31\%) reported to be slightly improved, 3 patients $(9 \%)$ reported no 
Table 2. Pain and Quality-of-Life Outcome Measures

\begin{tabular}{|c|c|c|c|c|c|}
\hline $\begin{array}{l}\text { Measuring } \\
\text { instrument }\end{array}$ & $\begin{array}{c}\text { Baseline score } \\
\text { Mean (SD) }\end{array}$ & $\begin{array}{l}\text { Follow-up score } \\
\text { Mean (SD) }\end{array}$ & $P$ & $\begin{array}{c}95 \% \text { CI of mean } \\
\text { difference }\end{array}$ & $\begin{array}{l}\text { Effect } \\
\text { size }\end{array}$ \\
\hline Pain intensity (VAS) & $7.6(1.4)$ & $4.2(2.6)$ & $<0.0001$ & 2.4 to 4.2 & 0.81 \\
\hline \multicolumn{6}{|l|}{ SF-36 } \\
\hline Physical functioning & $28.8(24.6)$ & $34.3(29.1)$ & NS & -15.4 to 4.4 & 0.07 \\
\hline Social functioning & $41.3(27.9)$ & $56.3(26.9)$ & 0.02 & -27.4 to -2.4 & 0.40 \\
\hline $\begin{array}{l}\text { Role limitations } \\
\text { physical }\end{array}$ & $7.5(18.7)$ & $26.7(38.8)$ & 0.007 & -32.7 to -5.6 & 0.47 \\
\hline $\begin{array}{l}\text { Role limitations } \\
\text { emotional }\end{array}$ & $59.5(44.8)$ & $64.3(47.1)$ & NS & -30.1 to 20.5 & 0.08 \\
\hline Mental health & $57.8(22.9)$ & $68.6(20.1)$ & 0.02 & -19.6 to -2.0 & 0.42 \\
\hline Vitality & $39.3(20.9)$ & $51.1(20.5)$ & 0.02 & -21.2 to -2.4 & 0.44 \\
\hline Bodily pain & $12.5(12.8)$ & $42.2(24.8)$ & $<0.0001$ & -37.8 to -21.7 & 0.81 \\
\hline General health & $50.5(15.8)$ & $45.9(21.7)$ & NS & -2.5 to 11.8 & 0.25 \\
\hline
\end{tabular}

NS = nonsignificant; SD = standard deviation; VAS = visual analog scale.

Table 3. Univariate Analyses for Success on Pain Intensity and GPE

\begin{tabular}{|c|c|c|c|c|c|c|c|c|}
\hline \multirow[b]{2}{*}{ Predictor } & \multicolumn{4}{|c|}{ Pain intensity } & \multicolumn{4}{|c|}{ GPE } \\
\hline & Successful, $n$ & $\begin{array}{c}\text { Not } \\
\text { successful, } n \\
\end{array}$ & $\chi$ & $P$ & Successful, $n$ & $\begin{array}{c}\text { Not } \\
\text { successful, } n\end{array}$ & $\chi$ & $P$ \\
\hline \multicolumn{9}{|l|}{ Gender } \\
\hline Male & 2 & 5 & 0.305 & 0.68 & 4 & 3 & 0.058 & 1.00 \\
\hline Female & 10 & 15 & & & 13 & 12 & & \\
\hline \multicolumn{9}{|l|}{ Education } \\
\hline High & 4 & 13 & 3.020 & 0.14 & 9 & 8 & 0.000 & 1.00 \\
\hline Low & 8 & 7 & & & 8 & 7 & & \\
\hline \multicolumn{9}{|l|}{ Localization } \\
\hline Hand & 6 & 9 & 0.075 & 1.00 & 9 & 6 & 0.536 & 0.50 \\
\hline Foot & 6 & 11 & & & 8 & 9 & & \\
\hline & Mean (SD) & Mean (SD) & $t$ & & Mean (SD) & Mean (SD) & $t$ & \\
\hline Age & $40.5(9.9)$ & $38.2(10.6)$ & -0.62 & 0.54 & $40.8(9.8)$ & $37.1(10.7)$ & -1.02 & 0.32 \\
\hline Pain duration, yr & $5.3(4.6)$ & $4.0(2.2)$ & -1.08 & 0.29 & $5.4(4.0)$ & $3.5(2.0)$ & -1.74 & 0.09 \\
\hline Pain intensity & $7.6(1.6)$ & $7.5(1.3)$ & -0.06 & 0.95 & $7.5(1.4)$ & $7.6(1.5)$ & 0.12 & 0.90 \\
\hline Pain catastrophizing & $34.4(4.9)$ & $29.0(12.0)$ & 1.50 & 0.15 & $30.1(10.4)$ & $32.1(10.2)$ & 0.55 & 0.59 \\
\hline
\end{tabular}

$\mathrm{SD}=$ standard deviation; $\mathrm{GPE}=$ global perceived effect.

change, and 2 patients $(6 \%)$ reported a worsening of their condition. Table 2 shows average pain intensity and the scores on the SF-36 domains at baseline (preimplantation) and at follow-up. Pain intensity was significantly reduced from baseline to follow-up. In addition, 9 mo after SCS, patients scored significantly higher on the SF-36 domains social functioning, role limitations physical, mental health, vitality, and bodily pain. The effect sizes show that improvement on the VAS, role limitations physical and bodily pain were clinically relevant.

\section{Prognostic Factors}

The results of the Kolmorgorov-Smirnov test, to ascertain whether PCS scores are normally distributed, showed a $P$ value of 0.97 , which allowed us to perform regression analyses. Table 3 summarizes the results of the univariate regression analyses to identify variables associated with successful outcome in pain intensity and GPE. The demographic variables were not predictive for any of the outcome measures. Next, multivariate logistic regression analyses were performed to predict successful pain relief and successful GPE, with pain duration and pain catastrophizing as the two independent variables. The regression model did not reach significance for pain intensity or GPE. Pain catastrophizing seemed unrelated to outcome of SCS in terms of pain relief and GPE.

Table 4 presents the multivariate regression analyses for the eight domains of the SF-36. All regression models included pain duration and the baseline score of the relevant SF-36 domain as control variables and catastrophizing as the crucial variable in the final model. Pain duration was found to be a significant predictor of social functioning and bodily pain at the follow-up. Moreover, for physical role limitations, vitality, and general health there was a nonsignificant trend for the association between pain duration and outcome. Patients with a longer duration of pain before SCS seem to profit more in various aspects of QOL. Pain catastrophizing was not predictive of any of the SF-36 domains at the follow-up.

Post hoc, we also tested whether any of the other demographic or pain-related variables were associated with outcome when these were entered instead of pain 
Table 4. Multivariate Regression Analyses for the Domains of the SF-36

\begin{tabular}{|c|c|c|c|c|}
\hline Dependent & Summary of the model & Predictors & $\boldsymbol{\beta}$ & $P$ \\
\hline \multirow{3}{*}{$\begin{array}{l}\text { Physical functioning } \\
\text { follow-up }\end{array}$} & \multirow[t]{3}{*}{$R^{2}=0.28, F=3.36, P=0.03$} & Pain duration & -0.01 & 0.96 \\
\hline & & Physical functioning baseline & 0.56 & 0.005 \\
\hline & & Catastrophizing & -0.11 & 0.55 \\
\hline \multirow[t]{3}{*}{ Social functioning follow-up } & \multirow{3}{*}{$R^{2}=0.20, F=2.26, P=0.10$} & Pain duration & 0.39 & 0.03 \\
\hline & & Social functioning baseline & 0.17 & 0.34 \\
\hline & & Catastrophizing & -0.01 & 0.94 \\
\hline \multirow{3}{*}{$\begin{array}{l}\text { Role limitations physical } \\
\text { follow-up }\end{array}$} & \multirow[t]{3}{*}{$R^{2}=0.26, F=3.11, P=0.04$} & Pain duration & 0.32 & 0.07 \\
\hline & & $\begin{array}{l}\text { Role limitations physical } \\
\text { baseline }\end{array}$ & 0.31 & 0.09 \\
\hline & & Catastrophizing & 0.18 & 0.29 \\
\hline \multirow{3}{*}{$\begin{array}{l}\text { Role limitations emotional } \\
\text { follow-up }\end{array}$} & \multirow{3}{*}{$R^{2}=0.03, F=0.28, P=0.84$} & Pain duration & 0.13 & 0.55 \\
\hline & & $\begin{array}{l}\text { Role limitations emotional } \\
\text { baseline }\end{array}$ & -0.05 & 0.81 \\
\hline & & Catastrophizing & -0.12 & 0.56 \\
\hline \multirow[t]{3}{*}{ Mental health follow-up } & \multirow[t]{3}{*}{$R^{2}=0.24, F=2.76, P=0.06$} & Pain duration & 0.23 & 0.19 \\
\hline & & Mental health baseline & 0.44 & 0.03 \\
\hline & & Catastrophizing & 0.21 & 0.29 \\
\hline \multirow[t]{3}{*}{ Vitality follow-up } & \multirow[t]{3}{*}{$R^{2}=0.19, F=1.97, P=0.15$} & Pain duration & 0.34 & 0.09 \\
\hline & & Vitality baseline & 0.41 & 0.05 \\
\hline & & Catastrophizing & 0.08 & 0.68 \\
\hline \multirow[t]{3}{*}{ Bodily pain follow-up } & \multirow[t]{3}{*}{$R^{2}=0.36, F=5.28, P=0.005$} & Pain duration & 0.41 & 0.01 \\
\hline & & Bodily pain baseline & 0.47 & 0.005 \\
\hline & & Catastrophizing & 0.06 & 0.72 \\
\hline \multirow[t]{3}{*}{ General health follow-up } & \multirow[t]{3}{*}{$R^{2}=0.37, F=4.81, P=0.009$} & Pain duration & 0.28 & 0.09 \\
\hline & & General health baseline & 0.59 & 0.002 \\
\hline & & Catastrophizing & -0.02 & 0.93 \\
\hline
\end{tabular}

catastrophizing, but no consistent predictive effect of any of these variables was found. Only education seemed to be related to general health at follow-up $(\beta=0.32 ; P=$ $0.04)$, with higher educated patients having a better general health at the follow-up.

\section{DISCUSSION}

This study examined whether pain catastrophizing is a predictor of SCS outcome in patients with CRPS-I. The results of this study showed that the efficacy of SCS in reduction of pain intensity, GPE, and QOL in a well-defined chronic CRPS-I population was not predicted by pain catastrophizing. For the SF-36 domains social functioning and bodily pain, pain duration seemed to be predictive, i.e., patients with a longer duration of pain profited more from SCS.

It has been suggested that pain catastrophizing may contribute to a negative emotional state, which is an important factor in the maintenance of CRPS and the responses to treatment. ${ }^{15}$ The influence of pain catastrophizing on outcome of treatment in CRPS has not yet been examined. However, there is evidence from other pain conditions that preintervention pain catastrophizing predicts postoperative pain after abdominal surgery ${ }^{30}$ and after total knee arthroplasy. ${ }^{31}$ More pertinent to this study, a few investigators have examined the influence of pain catastrophizing on treatment for chronic pain conditions. Two studies found pain catastrophizing to be a negative predictor of treatment efficacy; it reduced patients' subjective rating of success after multidisciplinary treatment for low-back pain $^{32}$ and was related to less pain reduction after radiofrequency lesions of the cervical spinal dorsal ganglion in cervicobrachialgia. ${ }^{33}$ Another study did not find an association between pain catastrophizing and outcome of high frequency transcutaneous electrical nerve stimulation in a chronic outpatient pain population. ${ }^{34}$

In this study, we were not able to find evidence for the hypothesized influence of pain catastrophizing on the outcome of SCS in patients with CRPS. It may be noted that baseline scores of the outcome pain intensity were lower and baseline scores of the SF-36 domains were higher, compared with mean scores in a chronic pain population found by Nicholas et al., ${ }^{35}$ except for role limitation emotional, mental health, and vitality. Also, the mean score of the PCS in this study was quite high (mean $=31$ ), indicating that patients with CRPS display a significant degree of pain catastrophizing. Indeed, compared with other chronic pain populations, where a median of 22 or 25 was found, in the present population $78 \%(n=25)$ of the patients obtained a score that was higher than $25 .^{36}$ It may be hypothesized that the absence of an effect results from the fact that almost all patients scored in the high catastrophizing range. It may also be proposed that especially in this population, catastrophizing may be secondary to the seriousness of the complaints and the repeated failures of previous treatments, leading patients to believe that CRPS is an untreatable and progressively deteriorating condition. ${ }^{15}$ The main pain duration was fairly long and possibly in less chronic patients the predictive value of pain catastrophizing could be present. Nevertheless, our results 
do demonstrate that SCS may have long-term positive effects in patients with CRPS-I despite high levels of pain catastrophizing.

QOL is an upcoming issue in chronic disease conditions. ${ }^{37}$ With regard to the impact of catastrophizing on QOL, findings in a large community sample with different pain subgroups and people without pain ${ }^{38}$ and in chronic pain population ${ }^{39}$ indicated that catastrophizing most prominently affects the mental and social aspects of QOL. In this study, we also found that pain catastrophizing was most closely related to mental health at baseline, although this correlation was moderate (Pearson's $r=-0.47$ ). However, there was no prospective relationship between pain catastrophizing and changes in QOL after treatment. The only prospective relation that we found in this study was between pain duration and social functioning and bodily pain at the follow-up. For pre- to postintervention changes in physical role limitations, vitality, and general health, a trend toward an association with pain duration was found. Patients suffering from pain for a longer period of time showed larger improvement on these aspects of QOL. This is in contrast to a previous study that found an inverse relationship between time from onset of first CRPS symptoms and efficacy of SCS. ${ }^{12}$ At present, we do not have an explanation for these controversial results.

Several limitations of this study should be acknowledged. First, we used a mail-out method to collect our data. Although we urged the patient to complete the questionnaire alone, without help of others, and complete every item, there is no control in the at-home situation, which may have biased the results. Second, given the observational character of this study, we cannot determine whether the therapeutic success of SCS as assessed on the VAS and the GPE is due to the specific effects of SCS, a placebo effect, a regression to the mean (spontaneous recovery), or a combination of these factors. Third, although the sample size $(n=32)$ in this study was sufficient to reach a large effect size $(r=0.50),{ }^{40}$ we were not able to detect medium and small effect sizes. However, considering the odds ratios that we found for successful pain relief and GPE, for both catastrophizing (odds ratio [OR] GPE = 0.98, CI: 0.92-1.81; OR VAS = 1.04, CI: 0.96-1.12) and pain duration (OR GPE = 1.29, CI: 0.92-1.81; OR $\mathrm{VAS}=1.23$, CI: $0.91-1.68$ ) as independent variables, we may conclude that the actual relationships are almost negligible and that the negative findings are not only due to a power problem.

Finally, we focused on a single psychological variable as a predictor of outcome. Although the selection of this variable was guided by theoretical considerations and based on the prior suggestion that pain catastrophizing is of critical importance in the maintenance of the primary features of CRPS, ${ }^{15}$ future studies could include other potentially important factors (e.g., depression). This study also has several strengths. First, there was a very high response rate, because returning the questionnaire was required for a first medical visit. Second, we used a well-defined CRPS-I population. Finally, we had a fairly long follow-up period $(9 \mathrm{mo}$ ) and thereby could really assess predictors of long-term efficacy of SCS.

This was the first study to test the assumption that pain catastrophizing may negatively affect responsiveness to treatment in CRPS. More specifically, we assessed its influence on long-term outcome after SCS. We found no evidence for the predictive value of pain catastrophizing for SCS outcome in terms of pain intensity, GPE, and QOL in patients with CRPS-I. Therefore, we conclude that a high level of pain catastrophizing in patients with CRPS-I is not a contraindication for SCS treatment.

APPENDIX: THE PAIN CATASTROPHIZING SCALE

\section{Pain Catastrophizing Scale}

Sullivan MJL, Bishop S, Pivik J. (1995)

\begin{tabular}{llll}
\hline Name: & Age: & Gender: \\
& & & \\
& & DMale $\square$ Female & \\
\hline
\end{tabular}

Everyone experiences painful situations at some point in their lives. Such experiences may include headaches, tooth pain, joint or muscle pain. People are often exposed to situations that may cause pain such as illness, injury, dental procedures or surgery. 


\begin{tabular}{|c|c|c|c|c|c|}
\hline RATING & $\mathbf{0}$ & $\mathbf{1}$ & $\mathbf{2}$ & $\mathbf{3}$ & $\mathbf{4}$ \\
\hline MEANING & Not at all & $\begin{array}{c}\text { To a slight } \\
\text { degree }\end{array}$ & $\begin{array}{c}\text { To a moderate } \\
\text { degree }\end{array}$ & $\begin{array}{c}\text { To a great } \\
\text { degree }\end{array}$ & All the time \\
\hline
\end{tabular}

When I'm in pain ...

\begin{tabular}{|c|c|c|}
\hline Number & Statement & Rating \\
\hline 1 & I worry all the time about whether the pain will end. & \\
\hline 2 & I feel I can't go on. & \\
\hline 3 & It's terrible and I think it's never going to get any better & \\
\hline 4 & It's awful and I feel that it overwhelms me. & \\
\hline 5 & I feel I can't stand it anymore & \\
\hline 6 & I become afraid that the pain will get worse. & \\
\hline 7 & 1 keep thinking of other painful events & \\
\hline 8 & 1 anxiously want the pain to go away & \\
\hline 9 & I can't seem to keep it our of my mind & \\
\hline 10 & I keep thinking about how much it hurts. & \\
\hline 11 & I keep thinking about how badly I want the pain to stop & \\
\hline 12 & There's nothing I can do to reduce the intensity of the pain & \\
\hline 13 & I wonder whether something serious may happen. & \\
\hline
\end{tabular}

Copyright 1995 Michael J.L. Sullivan. Reproduced with permission.

Source: Sullivan MJL, Bishop S, Pivik J. The pain catastrophizing scale: development and validation. Psychol Assess, 1995, 7

$524-532$

\section{REFERENCES}

1. de Mos M, de Bruijn AG, Huygen FJ, Dieleman JP, Stricker BH, Sturkenboom MC. The incidence of complex regional pain syndrome: a population-based study. Pain 2007;129:12-20

2. Stanton-Hicks M, Baron R, Boas R, Gordh T, Harden N, Hendler N, Koltzenburg M, Raj P, Wilder R. Complex regional pain syndromes: guidelines for therapy. Clin J Pain 1998;14:155-66

3. Geertzen JHB, Perez RSGM, Dijkstra PU, Kemler MA, Rosenbrand CJGM. Complex regional pain syndrome type I guidelines. Alphen aan den Rijn: Van Zuiden Communications BV, 2006

4. Lee AW, Pilitsis JG. Spinal cord stimulation: indications and outcomes. Neurosurg Focus 2006;21:E3

5. Stanton-Hicks MD, Burton AW, Bruehl SP, Carr DB, Harden RN, Hassenbusch SJ, Lubenow TR, Oakley JC, Racz GB, Raj PP, Rauck RL, Rezai AR. An updated interdisciplinary clinical pathway for CRPS: report of an expert panel. Pain Pract 2002;2:1-16

6. Stanton-Hicks M. Complex regional pain syndrome: manifestations and the role of neurostimulation in its management. J Pain Symptom Manage 2006;31:S20-4

7. Taylor RS. Spinal cord stimulation in complex regional pain syndrome and refractory neuropathic back and leg pain/failed back surgery syndrome: results of a systematic review and meta-analysis. J Pain Symptom Manage 2006;31:S13-9

8. Cruccu G, Aziz TZ, Garcia-Larrea L, Hansson P, Jensen TS, Lefaucheur JP, Simpson BA, Taylor RS. EFNS guidelines on neurostimulation therapy for neuropathic pain. Eur J Neurol 2007;14:952-70

9. Turner JA, Loeser JD, Deyo RA, Sanders SB. Spinal cord stimulation for patients with failed back surgery syndrome or complex regional pain syndrome: a systematic review of effectiveness and complications. Pain 2004;108:137-47

10. Kumar K, Hunter G, Demeria D. Spinal cord stimulation in treatment of chronic benign pain: challenges in treatment planning and present status, a 22-year experience. Neurosurgery 2006;58:481-96; discussion 496
11. Taylor RS, Van Buyten JP, Buchser E. Spinal cord stimulation for complex regional pain syndrome: a systematic review of the clinical and cost-effectiveness literature and assessment of prognostic factors. Eur J Pain 2006;10:91-101

12. Kumar K, Wilson JR. Factors affecting spinal cord stimulation outcome in chronic benign pain with suggestions to improve success rate. Acta Neurochir Suppl 2007;97:91-9

13. Doyles D. Psychological factors in spinal cord stimulation therapy: brief review and discussion. Neurosurg Focus 2006;21:1-6

14. North RB, Kidd DH, Wimberly RL, Edwin D. Prognostic value of psychological testing in patients undergoing spinal cord stimulation: a prospective study. Neurosurgery 1996;39:301-10; discussion 310-1

15. Bruehl S, Chung OY. Psychological and behavioral aspects of complex regional pain syndrome management. Clin J Pain 2006;22:430-7

16. Bruehl S, Husfeldt B, Lubenow TR, Nath H, Ivankovich AD. Psychological differences between reflex sympathetic dystrophy and non-RSD chronic pain patients. Pain 1996;67:107-14

17. Merskey H, Bogduk N. Classification of chronic pain: descriptions of chronic pain syndromes and definitions of pain terms. 2nd ed. Seattle: IASP press, 1994

18. Likert R. A technique for the measurement of attitudes. Arch Psychol 1932;22:140

19. Kemler MA, Barendse GA, van Kleef M, de Vet HC, Rijks CP, Furnee CA, van den Wildenberg FA. Spinal cord stimulation in patients with chronic reflex sympathetic dystrophy. N Engl J Med 2000;343:618-24

20. Van der Zee K, Sanderman R, Heyink J. De psychometrische kwaliteiten van de MOS 36-item short-form health survey (SF-36) in een Nederlandse populatie. T Soc Gez 1993;71:183-91

21. Van der Zee K, Sanderman R, Heyink J, Haes dH. Psychometric qualities of the Rand 36-item health survey 1.0: a multidimensional measure of general health status. Int J Behav Med 1996;3:104-22 
22. Aaronson NK, Muller M, Cohen PD, Essink-Bot ML, Fekkes M, Sanderman R, Sprangers MA, te Velde A, Verrips E. Translation, validation, and norming of the Dutch language version of the SF-36 health survey in community and chronic disease populations. J Clin Epidemiol 1998;51:1055-68

23. Essink-Bot ML, Krabbe PF, Bonsel GJ, Aaronson NK. An empirical comparison of four generic health status measures. The Nottingham Health Profile, the Medical Outcomes Study 36item Short-Form Health Survey, the COOP/WONCA charts, and the EuroQol instrument. Med Care 1997;35:522-37

24. Sullivan MJL, Bishop SR, Pivik J. The pain catastrophizing scale: development and validation. Psychol Assess 1995;7:524-32

25. Crombez G, Eccleston C, Baeyens F, Eelen P. When somatic information threatens, catastrophic thinking enhances attentional interference. Pain 1998;75:187-98

26. Lame IE, Peters ML, Kessels AG, Kleef M, Patijn J. Test-retest stability of the pain catastrophizing scale and the Tampa scale for Kinesophobia in chronic pain over a longer period of time. J Health Psychol 2008;13:820-26

27. Van Damme S, Crombez G, Vlaeyen J, Goubert L, Van den Broeck A, Van Houdenhove B. De pain catastrophizing scale: psychometrische karakteristieken en normering. Gedragstherapie 2000;3:211-22

28. Forouzanfar T, Weber WE, Kemler M, van Kleef M. What is a meaningful pain reduction in patients with complex regional pain syndrome type 1? Clin J Pain 2003;19:281-5

29. Rosnow RL, Rosenthal R. Beginning behavioural research: a conceptual primer. 5th ed. Englewood Cliffs, NJ: Pearson/Prentice Hall, 2005

30. Granot M, Ferber SG. The roles of pain catastrophizing and anxiety in the prediction of postoperative pain intensity: a prospective study. Clin J Pain 2005;21:439-45
31. Roth ML, Tripp DA, Harrison MH, Sullivan M, Carson P. Demographic and psychosocial predictors of acute perioperative pain for total knee arthroplasty. Pain Res Manag 2007;12:185-94

32. Hildebrandt J, Pfingsten M, Saur P, Jansen J. Prediction of success from a multidisciplinary treatment program for chronic low back pain. Spine 1997;22:990-1001

33. Samwel H, Slappendel R, Crul BJ, Voerman VF. Psychological predictors of the effectiveness of radiofrequency lesioning of the cervical spinal dorsal ganglion (RF-DRG). Eur J Pain 2000;4:149-55

34. Oosterhof J, Samwel HJ, de Boo TM, Wilder-Smith OH, Oostendorp RA, Crul BJ. Predicting outcome of TENS in chronic pain: a prospective, randomized, placebo controlled trial. Pain 2008;136:11-20

35. Nicholas MK, Asghari A, Blyth FM. What do the numbers mean? Normative data in chronic pain measures. Pain 2008;134:158-73

36. Van Damme S, Crombez G, Bijttebier P, Goubert L, Van Houdenhove B. A confirmatory factor analysis of the pain catastrophizing scale: invariant factor structure across clinical and non-clinical populations. Pain 2002;96:319-24

37. Kemler MA, de Vet HC. Health-related quality of life in chronic refractory reflex sympathetic dystrophy (complex regional pain syndrome type I). J Pain Symptom Manage 2000;20:68-76

38. Severeijns R, van den Hout MA, Vlaeyen JW, Picavet HS. Pain catastrophizing and general health status in a large Dutch community sample. Pain 2002;99:367-76

39. Lame IE, Peters ML, Vlaeyen JW, Kleef M, Patijn J. Quality of life in chronic pain is more associated with beliefs about pain, than with pain intensity. Eur J Pain 2005;9:15-24

40. Cohen J. Quantitative methods in psychology: a power primer. Psychol Bull 1992;112:155-9 